Soliman Junior, J., Baldauf, J.P., Formoso, C.T., Tzortzopoulos, P. (2018). "Using BIM and Lean for Modelling Requirements in the Design of Healthcare Projects" In: Proc. $26^{\text {th }}$ Annual Conference of the International. Group for Lean Construction (IGLC), González, V.A. (ed.), Chennai, India, pp. 571-581. DOI: doi.org/10.24928/2018/0455. Available at: www.iglc.net.

\title{
USING BIM AND LEAN FOR MODELLING REQUIREMENTS IN THE DESIGN OF HEALTHCARE PROJECTS
}

\author{
João Soliman Junior'1, Juliana P. Baldauf ${ }^{2}$, Carlos T. Formoso ${ }^{3}$, and \\ Patricia Tzortzopoulos ${ }^{4}$
}

\begin{abstract}
Healthcare facilities are well known for their complexity. Frequent changes in healthcare processes, as well as the introduction of new technologies, demand changes in the internal layout and in the performance of buildings. Moreover, there are several stakeholders involved, with distinct and sometimes conflicting requirements, including medical staff, patients, visitors, cleaning and maintenance teams, among others. Some of those requirements have been translated into a complex set of norms and regulations. This paper reports the initial results of an ongoing investigation that has explored opportunities for improving value generation in the design and installation of healthcare facilities by using BIM and Lean concepts. The aim of this study is to understand how user requirements can be modelled to support decision making in the design process. Modelling requirements involves several steps: identification, structuring, establishing priorities, translating and representing in a BIM model. It depends not only on the individual user requirements but also on how some critical healthcare processes have been defined. The main contributions of this paper are concerned with the definition of how different types of requirements can be modelled to support the assessment of the healthcare building designs.
\end{abstract}

\section{KEYWORDS}

BIM, requirements modelling, automated rule checking, healthcare design.

1 M. Sc. Student, School of Engineering, Building Innovation Research Unit (NORIE), Federal University of Rio Grande do Sul (UFRGS), Porto Alegre, Brazil, joao.juniorr@gmail.com

$2 \mathrm{PhD}$ Candidate, School of Engineering, Building Innovation Research Unit (NORIE), Federal University of Rio Grande do Sul (UFRGS), Porto Alegre, Brazil, julipbaldauf@gmail.com

3 Professor, School of Engineering, Building Innovation Research Unit (NORIE), Federal University of Rio Grande do Sul (UFRGS), Porto Alegre, Brazil, formoso@ufrgs.br

4 Professor, School of Art, Design and Architecture, University of Huddersfield, UK, P.Tzortzopoulos@hud.ac.uk 


\section{INTRODUCTION}

The healthcare built-environment is very well recognised for the complexity related to all phases of its life-cycle, including design, construction and operation. Thus, the impact of the built environment in healthcare services needs to be considered, due to the influence of the spaces over the healing process and healthcare outcomes (Tzortzopoulos et al. 2005). The demand for the fast introduction of emerging technologies on operations and changes in healthcare processes can lead to the need for many changes in the layout and building services. Additionally, the large number and variety of requirements from several different stakeholders, such as medical staff, patients, visitors, cleaning and maintenance teams, among others, must be considered during the design phase, increasing the complexity of the healthcare design process. Often those stakeholders have distinct or conflicting requirements, which makes the processes of capture and assessment difficult to perform. Furthermore, the iterative nature of the design process may result in the evolution of client requirements (Kiviniemi and Fischer 2004). In this context, traditional approaches for design and construction, which are usually manualbased with low use of information technology (IT), tend to become less effective regarding efficiency and value generation (Koskela and Howell 2002).

Value generation is one of the key elements of Lean Construction, being concerned with the fulfilment of client requirements (Koskela 2000). During the product development process, value generation consists of three phases, described by Leinonen and Huovila (2000) as: (i) identifying the clients' desires, needs and expectations; (ii) creating solutions that meet these requirements; and (iii) conducting assessment throughout the design and production process so that customer needs can be deployed in a final product, appropriated to those needs. Hence, this requires an approach towards client requirements management and modelling, which recognizes that requirements change and refinements are needed over time (Jallow et al. 2014). Client requirements management involves the process of managing, controlling and refining requirements throughout the product life cycle (Bruce and Cooper 2000). Requirements modelling should be understood as part of the requirements management process, and is related to requirements representation, which enables information to be better understood, manipulated and managed (Nuseibeh and Easterbrook 2000).

The use of IT has been suggested to support requirements management for a number of years. Kamara and Anumba (2001) indicate that using technology could support the creation, communication, documentation and management of requirements. Additionally, Kiviniemi (2005) suggests that the use of IT for managing requirements is desirable so that some degree of automation in manipulating a large amount of information is involved. Recent advances have discussed the use of Building Information Modelling (BIM) as a key approach to enhance quality and to deal with the complexity associated with healthcare projects. BIM allows requirements modelling through the development of a semantic-rich database, , which are not always explicit for decision making in the design process (Solihin and Eastman 2015). This information can be connected to building models, in order to provide a hierarchical structure to requirements data (Kiviniemi and Fischer 2004) and assess building designs, by using automated rule 
checking (Eastman et al. 2009). The aim of this paper is to understand how user requirements can be modelled to support decision making in order to facilitate the assessment of healthcare building designs. This paper reports the initial results of an investigation that explored opportunities for improving value generation in the design and installation of healthcare facilities by using BIM and Lean concepts.

\section{REQUIREMENTS MODELLING}

Requirements modelling was originally developed in the field of software engineering (Sommerville 2007). Several benefits of requirements modelling have been identified in that context, and it is believed that the construction industry could also benefit from it, such as: (i) simplicity in visualising requirements and making them available to the different stakeholders involved (Grässle et al. 2005); (ii) understanding and verifying requirements in terms of integrity, correctness and consistency (Grässle et al. 2005); and (iii) supporting the traceability of requirements, which reflects in the ease of finding their origin and destination (Sommerville 2007), as well as understanding how requirements evolve during design (Fiksel and Hayes-Roth 1993; Jallow 2011).

BIM can support the achievement of such benefits in construction, and its use for modelling information contributes to the visualisation and organisation of requirements data (Jallow et al. 2014). This can be beneficial both for design teams and also for professionals in charge of assessing building design (e.g. planning approvals). BIM-based requirements modelling has a positive impact on the verification step, as the connection between requirements and the building model enables automated visualisation and verification, and can thus reduce the time spent on the analysis and compliance of project proposals (Eastman et al. 2009). Besides, in the construction context, poor integration of shared information increase misunderstandings and allows information to be lost (Marchant 2016). There are other potential benefits, associated with mapping noncompliance specifications in the early stages of design, as well as allowing for different scenarios and experimenting with diverse design options with a larger input of information from the stakeholders (Zhang and El-Gohary 2015).

Thus, the storage of information on requirements structured in object-oriented tools contributes towards creating a construction industry that is more client-centred (Kiviniemi 2005; Parsanezhad et al. 2016). BIM-based tools such as dRofus ${ }^{\circledR}$ and Solibri ${ }^{\circledR}$ have been developed for this purpose (Parsanezhad et al. 2016). Both allow connecting requirements and different parts of the product model by using the IFC Open Standard, to ensure that the design solution satisfies the requirements (Kim et al. 2015). dRofus ${ }^{\circledR}$ is suitable for modelling requirements in a hierarchical tree structure, which can be used to represent the decomposition of non-functional requirements, such as safety and indoor thermal comfort, into technical-functional requirements, such as requirements related to dimensions of spaces (Eastman et al. 2009). By using Solibri ${ }^{\circledR}$, requirements can be connected to spaces and translated into logic rules such as some normative requirements of accessibility and space programme (Eastman et al. 2009). 


\section{RESEARCH METHOD}

Design Science Research (DSR) was the methodological approach adopted in this investigation. The main objective of DSR is to develop solution concepts that are able to solve classes of practical problems and at the same time allow a theoretical contribution to be made (Kasanen et al. 1993). In DSR, the main research outcome is an artefact, which is based on a deep understanding of problems from the real world (Lukka 2003).

The research process was divided according to the following phases: (i) understanding the problem; (ii) development of the artefact; and (iii) analysis and reflection. Several learning cycles are being undertaken during these stages, due to the iterative nature of this research approach, which is very similar to a design process. As this is an ongoing research effort, phases 2 and 3 are currently under development. An empirical study was conducted in close collaboration with a University Hospital in Porto Alegre, Brazil (Hospital A), which is undergoing a major process of redevelopment. An $84.000 \mathrm{~m}^{2}$ extension in the hospital complex is being built, corresponding to an increase of $70 \%$ in the existing built area. This study started in January 2016 and has focused on the Emergency Unit, including both current and future spaces.

Multiple sources of evidence were used in this investigation, such as: (i) 26 unstructured and 6 semi-structured interviews with the hospital staff and architecture and engineering team members; (ii) document analysis (2D and 3D designs, internal operational process descriptions, regulation RDC 50, reports from the hospital staff to the design teams, regarding design modifications); (iii) design assessment reports; (iv) direct observations at the emergency unit, in order to identify new user requirements and assess previous captures; and (v) meetings with engineers, architects and contractors from the undergoing expansion construction project. Five main activities were developed so far, and they are mostly related to the first and second phases of the research process: (i) identification and understanding of the requirements from internal and external clients and the associated healthcare regulations; (ii) structuring and modelling requirements with support of dRofus ${ }^{\circledR}$; (iii) modelling the building project up to LOD 350 with support of Autodesk Revit; (iv) translation and modelling of rules in order to perform an automated checking process, with support of Solibri Model Checker ${ }^{\circledR}$; and (v) assessing the design project regarding the attendance of requirements from both clients and regulations.

\section{EMPIRICAL STUDY: HOSPITAL A}

\section{REQUIREMENTS IDENTIFIED AT THE EXISTING EMERGENCY UNIT}

From the interviews and observations made in the existing emergency unit, as well as information from documents containing requests for changes on the future emergency project, items of users' needs were identified. This information is related to different elements such as: (i) environmental comfort; (ii) accessibility; (iii) visual requirements, as wayfinding' needs; (iv) furniture quality and ergonomics; (v) space programme; (vi) suitability to use and functionality of spaces; (vii) furniture and equipment; (viii) fluidmechanical installations; (ix) privacy; (x) infrastructure; and (xi) proximity/distances 
between spaces and functions. The information collected was interpreted and translated into 177 requirements. This is an important activity so that requirements can be understood and interpreted by people and modelled on computer-based tools (Fiksel and Hayes-Roth 1993; Kamara et al. 2002).

\section{REQUIREMENTS IDENTIFIED IN HEALTHCARE REGULATIONS}

Codes and regulations for healthcare projects usually contain a large number of requirements, which play a key role in the design for this type of building. The RDC 50 standard, from the Brazilian Health Surveillance Agency, was analysed. This is the most important set of codes and regulations for healthcare projects in the Brazilian context. 864 regulations were identified, 1284 requirements stemmed from these. These requirements are related to: (i) legal aspects of healthcare projects; (ii) existence of certain installation systems (such as medical gases, hot and cold water supply, HVAC, MEP, furniture, fixture and equipment) in specific rooms, according to the activities which shall be executed on each space; (iii) space programme, specifying minimum spaces and areas; and (iv) design and performance criteria for supporting systems, such as fire safety system.

\section{REQUIREMENTS MODELLING}

Modelling requirements included (i) requirements structuring and classification; (ii) connecting requirements with the building model; and (iii) encoding requirements into logic rules. These are described as follows.

\section{Requirements structuring and Classification}

Users' requirements were organised in a structured way, which contains different levels of detail. Initially, the information was stored in a spreadsheet and grouped according to affinity, such as requirements related to the dimensions of the spaces and, subsequently, it was organised into categories and subcategories of requirements.

These categories and subcategories were based on Kiviniemi's (2005) framework, as well as on the existing structure of dRofus ${ }^{\circledR}$. As a result, the requirements' structure adapted to healthcare projects includes 13 categories, 32 subcategories (Figure 1). The subcategories are broken down into in 177 requirements.

\begin{tabular}{|c|c|c|}
\hline Categories & Subcategories & $\begin{array}{l}\text { Quantity of } \\
\text { requirements }\end{array}$ \\
\hline 1. Conformity space requirements & 1.1. Requested location; 1.2. Occupancy; 1.3. Adequacy of Space dimensions; 1.4. Number of space units & 60 \\
\hline 2. Equipment and furniture requirements & $\begin{array}{l}\text { 2.1. Equipment and furniture in space; 2.3. Ergonomics; 2.4. Equipment and furniture dimensions; } \\
\text { 2.5. Operation and maintenance of furniture and equipment }\end{array}$ & 48 \\
\hline 3. Plumbing/piping systems requirements & 3.1. Plumbing systems; 3.2 . Medical gas pipeline systems & 6 \\
\hline 4. Flexibility of Building, Spaces and Technical Systems & 4.1. Expandability, 4.2. Frame flexibility; 4.3. Alternative use & 6 \\
\hline 5. Acoustics & 5.1. Noise level & 1 \\
\hline 6. Lighting and Electrical Systems & 6.1. Lighting; 6.2. Electrical Systems & 7 \\
\hline 7. Indoor climate & 7.1. Heating and Cooling & 1 \\
\hline 8. Operation and maintenance & 8.1. Cleaning & 1 \\
\hline 9. Visual requirements & 9.1. Internal/ external visual contacts; 9.2. Wayfinding; 9.3. Visual signal; 9.4. Visual control; 9.5. Visual barrier & 21 \\
\hline 10. Accessibility requirements & 10.1. Space Accessibility; 10.2. Building Accessibility; 10.2. Equipments and furniture Accessibility & 14 \\
\hline 11. Finishing requirements & 11.1. Floor, 11.2. Walls and partitions & 5 \\
\hline 12. Doors and windows requirements & 12.1. Doors; 12.2. Windows & 4 \\
\hline 13. Information technology & 13.1. Scope of IT; 13.2. Computerized services & 3 \\
\hline
\end{tabular}

Figure 1: Structure of user requirements with categories and sub-categories adapted to healthcare projects. Developed by the authors. 


\section{Connecting Requirements to the Building Model}

The spaces, equipment, furniture and installations planned in $\mathrm{dRofus}^{\circledR}$ can be connected with the building model. On selecting one of the spaces, dRofus ${ }^{\circledR}$ opens a window called Room Data Sheet (RDS), onto which requirements are stored. RDS includes functional categories, such as Conformity Space Requirements, in which requirements were stored in a structured way (Figure 2). The organisation of requirements in dRofus ${ }^{\circledR}$ also allows the insertion of new requirements that may arise throughout the design process.

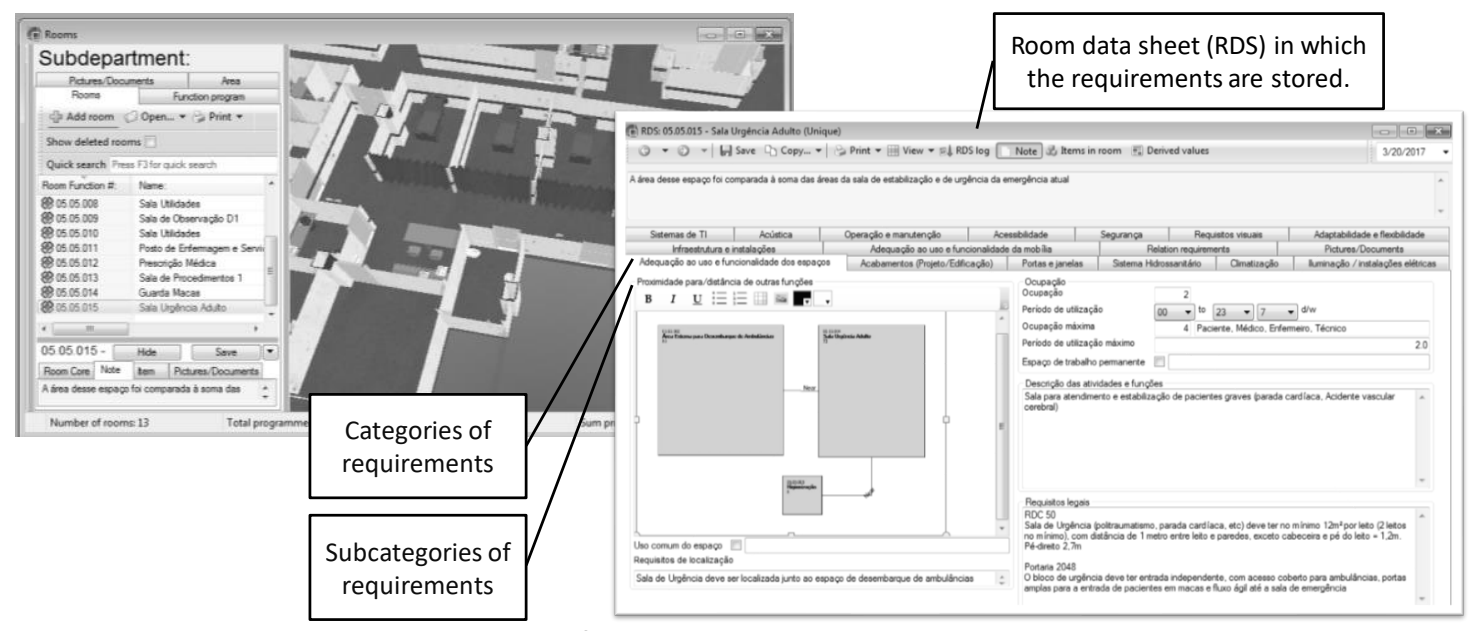

Figure 2: Requirements stored in dRofus ${ }^{\circledR}$ and connected with building model. Developed by the authors.

\section{Encoding Requirements to Logic Rules}

The process of encoding requirements into logic clauses was made to allow a rulestructure definition, this was based on the atomic sentence concept. This type of sentence is a declarative clause that can only be true or false and is the "minimum unit" of a logicbased expression, in other words, it cannot be divided into other simpler sentences (Park et al. 2016). An atomic sentence usually is expressed under the structure of S (subject) + $\mathrm{V}$ (verb) $+\mathrm{O}$ (object) (Lee et al. 2016). More than that, these expressions should consist of the content and the condition to be verified.

The process of defining atomic sentences is based on the meaning of requirements' elements. Thus, it relies on semantic principles, as semantics can be defined as "meanings of terminologies" (Chen and Vernadat 2003). Based on the encoded logic rules, there are different approaches which can be adopted to perform the automated design assessment: (i) re-write logic clauses, which are the output of translating requirements based on semantics, into a computer-executable algorithm; or (ii) using logic clauses in order to support the input of data into a code checking software, such as Solibri Model Checker ${ }^{\circledR}$.

\section{ASSESSING THE BUILDING DESIGN}

Once the requirements were modelled and connected to the building design, structured information became available, which enabled the assessment of the design. The task of verifying semantic-rich data in the 3D model is not an easy step in the assessment process and sometimes might result in inconsistent outputs. Thus, for this empirical study, the assessment process was made by using three different approaches: (a) automated 
checking; (b) semi-automated checking; and (c) manual checking. Combining different techniques was important, as all approaches have their limitations. These are described as follows.

\section{Automated Checking}

The use of automated rule-checking in this study was carried out with the support of Solibri Model Checker ${ }^{\circledR}$. A wide range of codified requirements was inserted in the software "ruleset manager", in which rules can be modelled according to its internal programming structure. The use of automated systems is promising due to the possibility of providing more coherent results, with little or no ambiguity in the assessment reports.

In this study, Solibri ${ }^{\circledR}$ was successfully used to verify requirements related to accessibility, properties of spaces and installation of systems in specific areas. Figure 3 presents an example of requirement checking: "the invasive treatment room needs to contain: cold water supply system, two oxygen outlets per bed, one outlet for nitrous oxide for every two beds, and two outlets of medical compressed air per bed.".

The main issue regarding the use of automated rule-checking systems, especially hard-coded approaches such as Solibri Model Checker ${ }^{\circledR}$, is that some of the healthcare requirements are too complex and subjective to adapt to the software demands. Besides, rule creation under the Solibri ${ }^{\circledR}$ interface is an example of what is called a "black-box effect", already described by the literature (Lee et al. 2016; Solihin and Eastman 2016). This happens because "processing rules" becomes an invisible task, the user just receives a report with a pass, fail or inconclusive status, and the actual checking process is hidden within the software programming logic.

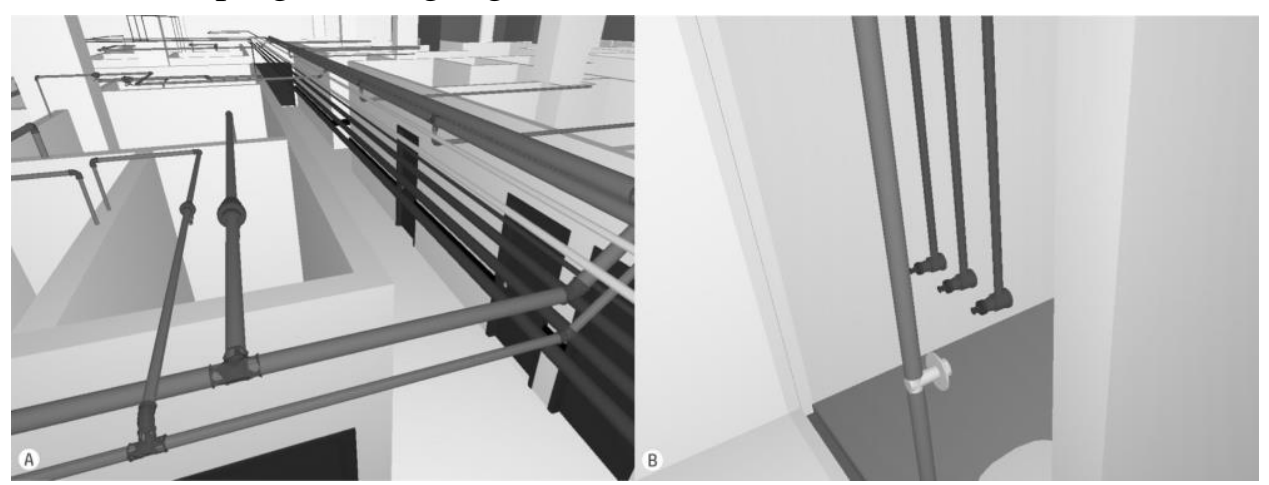

Figure 3: automatic rule-based verification of cold water supply system (A) and medical gases supply (B). Developed by the authors.

\section{Semi-automated Checking}

Semi-automated checking can be defined as a human judgment which is made by assessing computer-processed data. The main difference from the automated rulechecking process relies upon who is responsible for the pass or fail status, i.e. the judgment. This approach was used in the study for situations in which it was possible to use structured data from both the 3D model itself, as well as from the modelled requirements, to verify certain criteria with some degree of subjectivity. As an example, it was possible to compare the programmed area with the actual designed area, under 
computable-processed information from dRofus ${ }^{\circledR}$. In this approach, the final decision depends on human interpretation and judgment.

\section{Manual Checking}

Manual checking can be seen as the opposite of automated rule-checking. The use of manual checking in this study was restricted to some highly-subjective requirements, which could not be verified in either the automated and semi-automated methods. This approach, despite being necessary because of the complexity levels involved in the healthcare context, usually demands more time to perform the design assessment. More than that, manual checking is not replicable, which means each modification or new design must be verified through a completely new set of steps, instead of reusing the rulestructure, which increases even further the efforts put into the assessment process. Additionally, understanding and interpreting the content of requirements sometimes can lead to inconsistency and can be prone to incorrect outputs, because of subjective human interpretation and judgment.

An example of manual checking adopted in this study: there are requirements from the users related to design such as, (i) drawers shall be easy to open; and some are related to operation, (ii) furniture shall function properly in order to avoid noise emission to the patients. These requirements are highly subjective, and their assessment on the design relies upon the particular interpretation of their content and conditions against related design specifications.

\section{Analysis of the Assessment Process}

In relation to the 177 user requirements identified in this research, $23 \%$ were able to be automatically checked, and a further $23 \%$ could be verified by semi-automated checking. It is noted that BIM-based tools were important in the assessment process, as $46 \%$ of requirements could be verified by automated and semi-automated methods, while $54 \%$ of user's requirements still required manual checking, because of the subjectivity related to the requirements.

Regulatory requirements were analysed based on the possibility of translating requirements into logic rules. This analysis was made based on the levels of subjectivity necessary to assess the requirement in the design, as well as the possibility of re-writing sentences into logic clauses. Based on that, $63 \%$ of requirements could be translated into logic rules. Of these requirements, $39 \%$ were qualitative, $53 \%$ quantitative and $8 \%$ were ambiguous.

\section{CONCLUSIONS}

The process of modelling requirements allows structuring, classifying and checking semantic-rich information on design projects. While Lean is a fundamental background for developing these activities, its associated use with BIM-based tools appears to be a promising way of mitigating some of the negative effects of complex systems such as those observed in the healthcare context, by means of providing some degree of automation, as suggested by Kiviniemi (2005). Moreover, the relationship between Lean 
and BIM is even more important, because automated processes for structuring requirements and assessing designs, such as those presented by this paper, may provide opportunities to minimize waste during the design process and to increase the overall quality of healthcare projects, as well as a means of ensuring that design specifications will fulfil diverse clients' needs. In other words, this is an opportunity of increasing value for the customer, which is imperative within the Lean Philosophy.

Even though automation is desirable, the findings of this study indicate that currently not all requirements can be fully translated in terms of automated rule processing and checking. Although this decreases the overall degree of automation in the processes, this fact may provide benefits to the healthcare context. In some complex situations, a fully automated scenario could not allow human-creative solutions to emerge. In other words, the attendance of some of the requirements relies on subjectivity, which depends on human interpretation and creativity, or artificial intelligence techniques, in order to be fully considered in the design.

Thus, assessing the conformity of healthcare designs to clients' requirements involves some degree of subjectivity, while it is possible to introduce some degree of automation. Future research should focus on finding a suitable balance, considering the positive and negative impacts of automation and subjectivity on the requirements modelling tasks to be performed. Therefore, there is a need for further research into the use of BIM for modelling the diversity of connections between functional and non-functional requirements of the model, in order to better identify how this can contribute to the quality of healthcare projects and the associated impacts on the value generation process.

\section{ACKNOWLEDGMENTS}

We would like to thank CNPq for the financial support for this research, dRofus $\mathrm{AS}^{\circledR}$ and Solibri ${ }^{\circledR}$ for the software support and the Hospital staff, architecture and engineering team members, for the collaboration and the opportunity to develop this investigation.

\section{REFERENCES}

Barrett, P., Hudson, J., and Stanley, C. (1999). "Good practice in briefing: the limits of rationality." Automation in Construction, 8(6), 633-642.

Bruce, M., and Cooper, R. (2000). Creative product design: a practical guide to requirements capture management. Chinchester: John Wiley, 2000.

Chen, D., and Vernadat, F. B. (2003). "Enterprise Interoperability: A Standardisation View." Enterprise Inter- and Intra-Organizational Integration, K. Kosanke, R. Jochem, J. G. Nell, and A. O. Bas, eds., Springer US, Boston, MA, 273-282.

Eastman, C., Lee, J., Jeong, Y., and Lee, J. (2009). "Automatic rule-based checking of building designs." Automation in Construction, 18(8), 1011-1033.

Fiksel, J., and Hayes-Roth, F. (1993). "Computer-aided Requirements Management." Concurrent Engineering, 1(2), 83-92.

Grässle, P., Baumann, H., and Baumann, P. (2005). UML 2.0 in Action A project based Tutorial. 
Jallow, A. K. (2011). "Integrated lifecycle requirements information management in construction."

Jallow, A. K., Demian, P., Baldwin, A. N., and Anumba, C. (2014). "An empirical study of the complexity of requirements management in construction projects." Engineering, Construction and Architectural Management, 21(5), 505-531.

Kamara, J. M., and Anumba, C. J. (2001). "ClientPro: a prototype software for client requirements processing in construction." Advances in Engineering Software.

Kamara, J. M., Anumba, C. J., and Evbuomwan, N. F. O. (2002). Capturing client requirements in construction projects. Thomas Telford Publishing, London.

Kasanen, E., Lukka, K., and Siitonen, A. (1993). "The Constructive Approach in Management Accounting Research." Journal of Management Accounting Research.

Kim, T. W., Kim, Y., Cha, S. H., and Fischer, M. (2015). "Automated updating of space design requirements connecting user activities and space types." Automation in Construction, Elsevier B.V., 50, 102-110.

Kiviniemi, A. (2005). "Requirements Management Interface to Building Product Models." Stanford University.

Kiviniemi, A., and Fischer, M. (2004). "Requirements Management Interface to Building Product Models." 1-12.

Koskela, L. (2000). "An Exploration towards a Production Theory and its Application to Construction.” VTT Building Technology, VTT Technical Research Centre of Finland, Espoo, Finlândia, 298.

Koskela, L., and Howell, G. (2002). "The theory of project management: Explanation to novel methods." Proceedings IGLC, 1-11.

Lee, H., Lee, J. K., Park, S., and Kim, I. (2016). "Translating building legislation into a computer-executable format for evaluating building permit requirements." Automation in Construction, Elsevier B.V., 71, 49-61.

Leinonen, J., and Huovila, P. (2000). "Requirements management in life-cycle design." VTT: Building Technology, Finland.

Lukka, K. (2003). "The constructive research approach." Case study research in logistics. Publications of the Turku School of Economics and Business Administration, Series $B, 1(2003), 83-101$.

Marchant, D. (2016). "The design brief: Requirements and compliance." Journal of Information Technology in Construction, 21(November), 337-353.

Nuseibeh, B., and Easterbrook, S. (2000). "Requirements Engineering : A Roadmap."

Park, S., Lee, Y. C., and Lee, J. K. (2016). "Definition of a domain-specific language for Korean building act sentences as an explicit computable form." Journal of Information Technology in Construction, 21(September), 422-433.

Parsanezhad, P., Tarandi, V., and Lund, R. (2016). "Formalized requirements management in the briefing and design phase, a pivotal review of literature." Journal of Information Technology in Construction, 21(May), 272-291.

Solihin, W., and Eastman, C. (2015). "Classification of rules for automated BIM rule checking development." Automation in Construction.

Solihin, W., and Eastman, C. M. (2016). "A knowledge representation approach in BIM rule requirement analysis using the conceptual graph.” Journal of Information 
Technology in Construction, 21(March), 370-401.

Sommerville, I. (2007). Software Engineering. Addison-Wesley Publishing Company, Wokingham, England.

Tzortzopoulos, P., Chan, P., and Cooper, R. (2005). "Requirements management in the design of primary healthcare facilities." SIBRAGEC.

Zhang, J., and El-Gohary, N. M. (2015). "Automated Information Transformation for Automated Regulatory Compliance Checking in Construction." Journal of Computing in Civil Engineering, 29(4). 